\title{
Correction to: Which is heterogeneous, stress or strength? An estimation from high-density seismic observations
}

Yoshihisa lio ${ }^{1 *}$, Itaru Yoneda ${ }^{1}$, Masayo Sawada' ${ }^{1}$ Tsutomu Miura' ${ }^{1}$ Hiroshi Katao ${ }^{1}$, Yoichiro Takada², Kentaro Omura ${ }^{3}$ and Shigeki Horiuchi ${ }^{4}$

Correction to: Earth, Planets and Space (2017) 69:144 https://doi.org/10.1186/s40623-017-0730-3

After publication of this work (Iio et al. 2017), an error was noticed. Figures 10 and 12 were accidentally swapped. This was caused due to a typesetting error.
This is now corrected below (Figs. 10, 12):

The publisher apologises for these errors.

*Correspondence: iio@rcep.dpri.kyoto-u.ac.jp

${ }^{1}$ Research Center for Earthquake Prediction, Disaster Prevention Research

Institute, Kyoto University, Uji, Japan

Full list of author information is available at the end of the article 


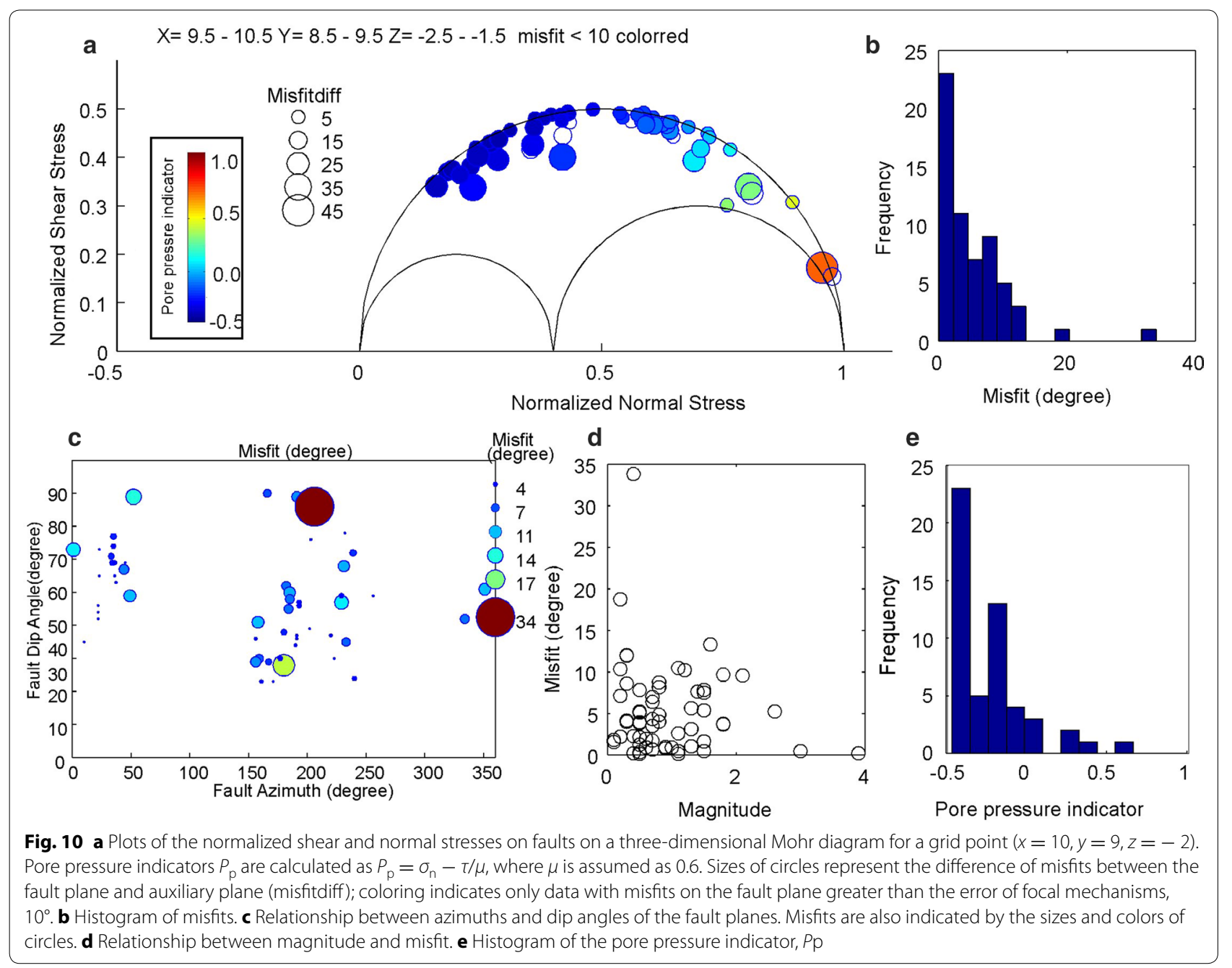




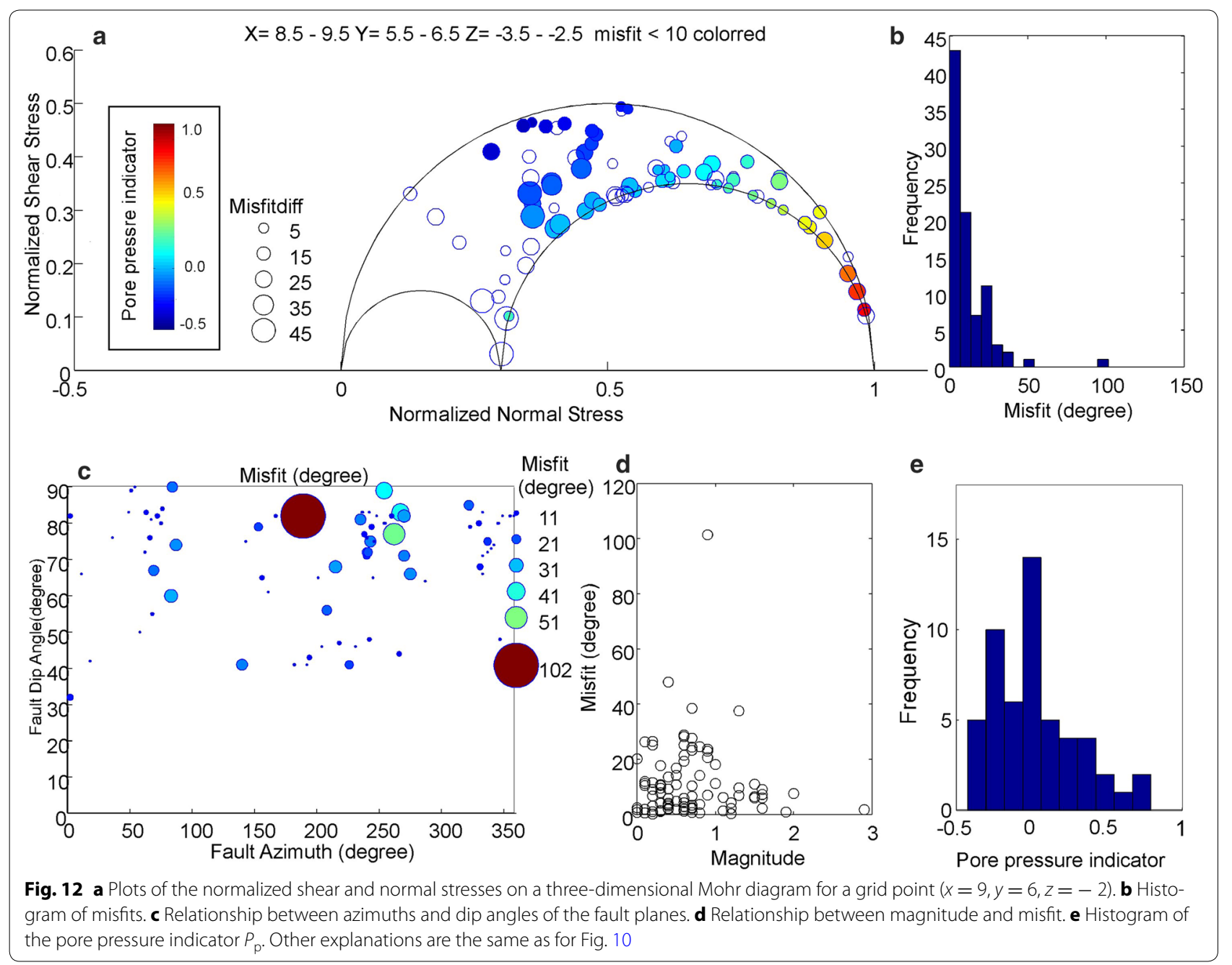

\section{Author details}

${ }^{1}$ Research Center for Earthquake Prediction, Disaster Prevention Research Institute, Kyoto University, Uji, Japan. ${ }^{2}$ Department of Earth and Planetary Sciences, Hokkaido University, Sapporo, Japan. ${ }^{3}$ National Research Institute for Earth Science and Disaster Prevention, Tsukuba, Japan. ${ }^{4}$ Home Seismometer, Fukushima, Japan.

The original article can be found online at https://doi.org/10.1186/ s40623-017-0730-3.

\section{Publisher's Note}

Springer Nature remains neutral with regard to jurisdictional claims in published maps and institutional affiliations.
Received: 3 January 2018 Accepted: 3 January 2018

Published online: 07 February 2018

\section{Reference}

lio Y, Yoneda I, Sawada M, Miura T, Katao H, Takada Y et al (2017) Which is heterogeneous, stress or strength? An estimation from high-density seismic observations. Earth Planets Space 69:144 